\title{
Electric Power Safety Research and Development of Simulation and Training Platform
}

\author{
Songxue Hou, Shunchao Wang, DanXu, YingWang, Qibin Yang
}

Technical training center of Hubei electric power company, Wuhan 430079

Keywords: safety accidents,skill training system,computer simulation technology.

\begin{abstract}
Safety accidents are much more than general occasions, therefore strengthen the simulation training safety technology training,which could make the worker familiar with tools of production safety operating rules,is particularly urgent!Electric marketing skill training is an important part to keep electricity safe. Here computer simulation technology is used in skill training system and a new training mode is put forward. The background of computer simulation training system is described. The system's structure and working principle are presented.
\end{abstract}

\section{Introduction}

With the rapid development of economy, the demand of electricity in each industry is becoming higher and higher. On the basis of ensuring high quality electric power, continuous power supply is required to ensure the safety and stable operation of industrial and agricultural production. Modern power grid is becoming more and more complicated and intelligent. The requirements of protection and operation skills are becoming higher and higher day after day in electric power enterprise staff. Therefore, the electric power enterprise should improve the power marketing skill of electric power personnel and further improve the safety awareness, which can effectively prevent the occurrence of on-site safety accidents.

Traditional training is carried out by opening classes taught by the experienced select. This kind of traditional electric power marketing training method is now unable to meet the actual production needs, mainly in the following respects: outdated training,single training method,operational skills training needs to be strengthened,lacking of flexibility and training feedback.Simulation training platform can overcome the above shortcomings. It has been applied in charged operation training, transmission and distribution lines, electrical safety training and so on, which achieves good results.

On the basis of comprehensive investigation, analysis and summary, this paper combines existing basic conditions and training needs. And the paper introduces the concept of "risk experience" training into the field of electric marketing training. Under the premise of safety, introducing of computer technology, multimedia technology and virtual reality technology, developing virtual simulation training system software and hardware, makes the trainees in the training process see the serious consequences of dangerous operation more intuitive. Based on virtual reality platform tools, the training is achieved through computer simulation. After using 3D modeling tool virtualization to virtualize the actual scene and practical training equipment, trainees can operate on the training platform by using a variety of sensors in the virtual space.

\section{The process framework of the training platform}

The process framework of the simulation platform consists of two large blocks: training test information management and simulation system, as shown in figure 1.

According to the above business architecture design, training the test information management and simulation system constitute power security simulation and training system platform layer. And they support on-site power simulation training of safety business. 


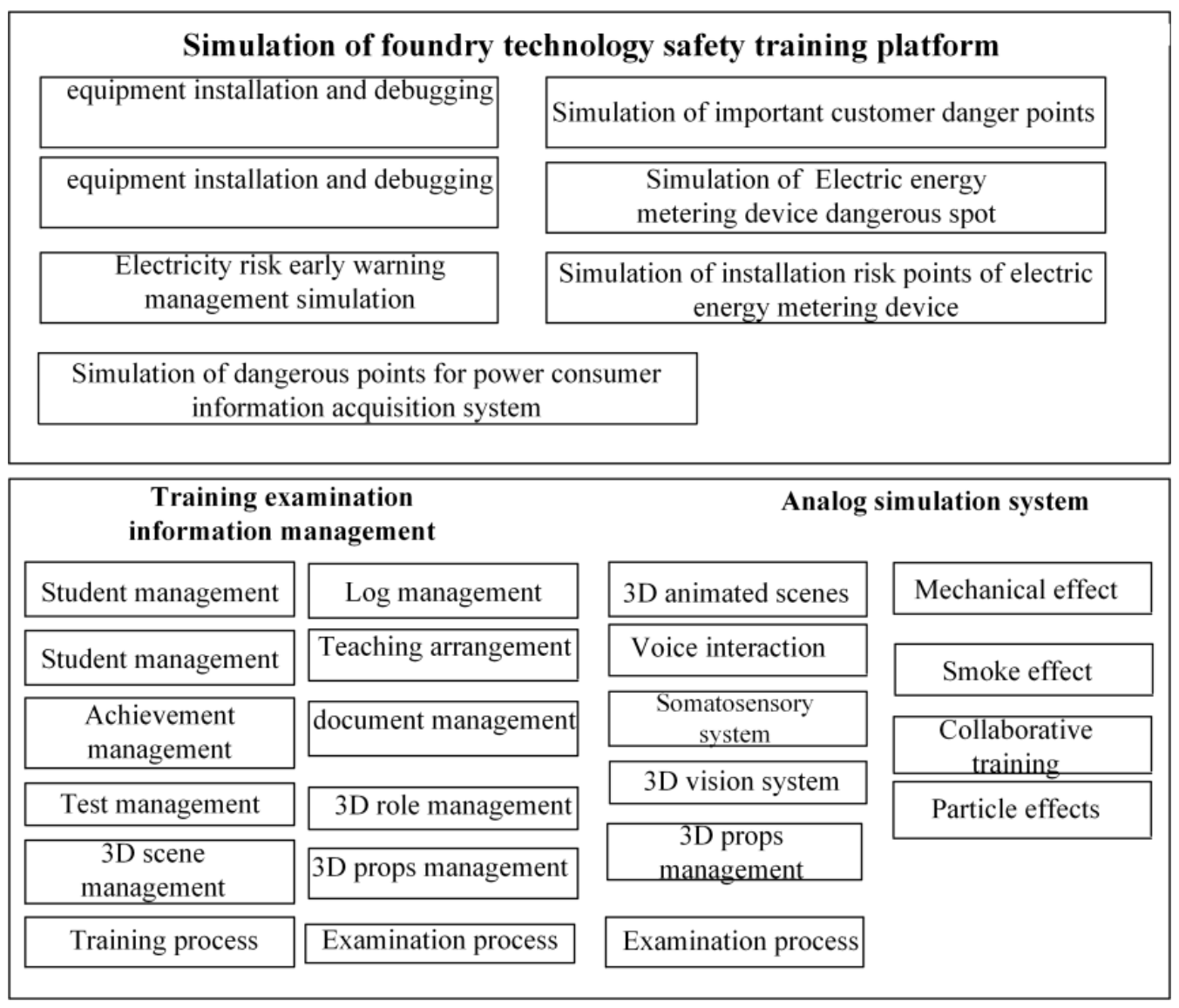

Figure 1 Electric power security simulation and training platform business framework

\subsection{Multiple independent practice scenarios}

In this scenario, the trained personnel can enter the system independently into the actual training scene for the actual training and examination, and the logical topology diagram is shown in figure 2 .

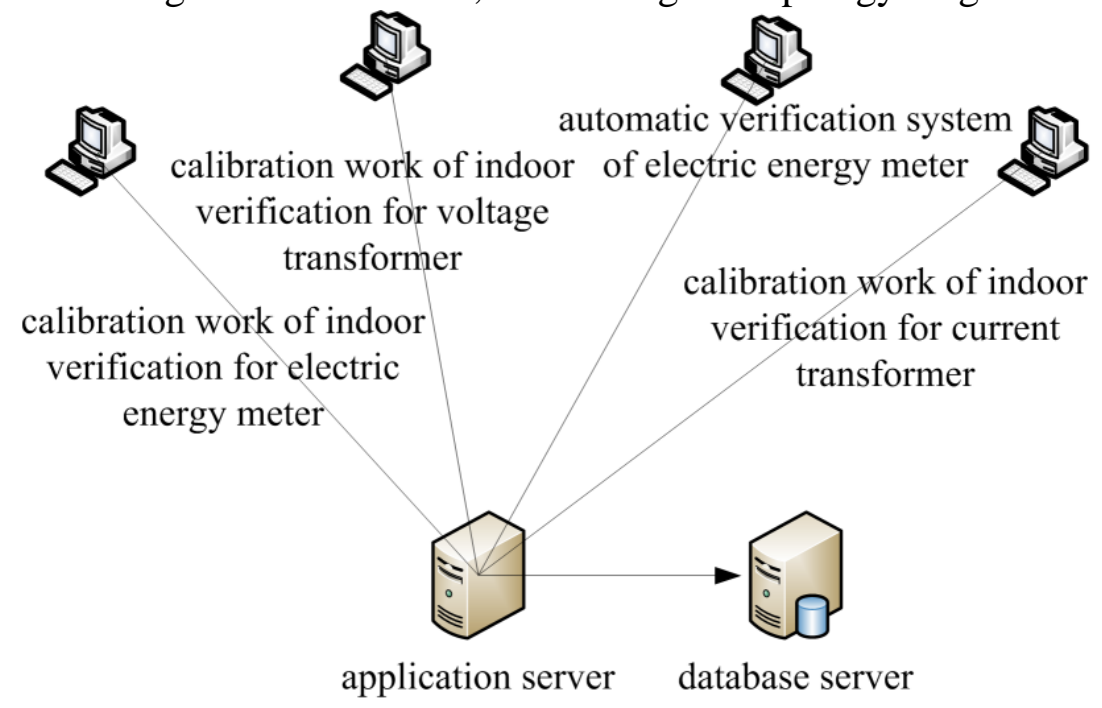

Figure.2 .Logical topological graph of multiplayer training scenario

As shown above, in this scenario, the participant's characters can enter different training scenarios to implement the actual training and test business requirements. The student role can be operated independently in a particular scenario, and the manipulation information will be logged and stored in the database server,which will be achieved by the application server. The teacher can also enter into the actual training scene of a participant, the teacher view can be used to observe the results of the completed operation, and bind to the student's perspective to view the process.

In this scenario, participants can conduct the exam independently. The participants can complete 
the exam questions which setted in the scene, and the results will be recorded in the database of the exam system. Students and teachers can use the web system to check their answers and grades.

\subsection{Multi-machine online training scenario}

This scene is used for teachers to teach all the students. The logical topology diagram is shown in figure 3.

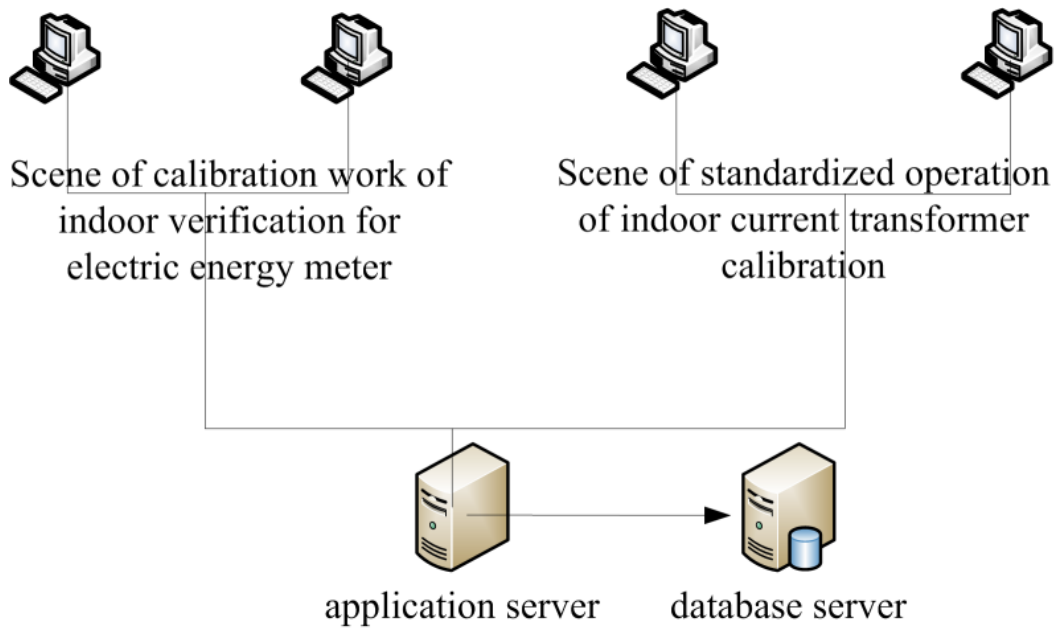

Figure.3 .Logical topological graph of multi machine online training scenario

In this scenario, the students' view is bound to the teacher, in other words, the participant' view is changed by the control of the teacher. The view of all the students is consistent and teachers can do the same teaching activities.

\subsection{Multi-machine interactive training scene}

This scenario is used for multiple students training collaborating with each other. In practice, there are a lot of scenarios which need multiple individuals to work together. In a virtual scenario, multiple people are required to enter the same scenario to complete a task. The logical topology diagram is shown in figure 4.

As shown in figure 4, students can be grouped into different training scenarios. Each of the actual training scenarios is available for multiple partners to complete a practical training mission. The teacher can also enter the actual training scene of a participant. The teacher's perspective can be used to view the results of the participants' actions. And it can bind to the students' perspective to view the operation process of the participant.

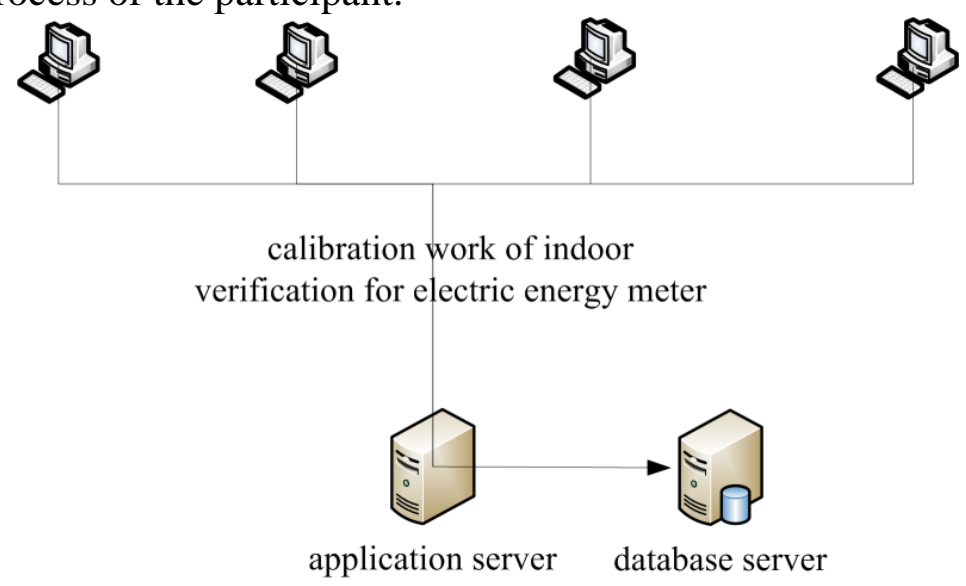

Figure.4 .Logical topological graph of multi machine online training scenario

\section{Training platform application architecture}

The application architecture is summarized on the basis of analyzing the business architecture to 
extract the collection of the application modules. The application modules in this collection are interrelated and coordinated. Each of the modules has an independent functions in logical, which can meet the requirements of the system. According to the business analysis, the application architecture of the actual training platform is shown in figure 5.

\begin{tabular}{|c|c|c|c|c|c|c|c|}
\hline Business layer & \multicolumn{2}{|c|}{$\begin{array}{l}\text { simulation of equipment } \\
\text { installation and debugging }\end{array}$} & \multicolumn{2}{|c|}{$\begin{array}{l}\text { equipment operation and } \\
\text { simulation management }\end{array}$} & \multicolumn{2}{|c|}{$\begin{array}{l}\text { teaching } \\
\text { arrangement }\end{array}$} & $\cdots$ \\
\hline Application layer & test questions & scene prop & roduction & examination & training & \multicolumn{2}{|c|}{ achievemer } \\
\hline \multirow{3}{*}{ Platform layer } & 3D scene & & & particle system & \multicolumn{3}{|c|}{ phonetic system } \\
\hline & role & $3 \mathrm{D}$ & & smog system & \multicolumn{3}{|c|}{ cooperative system } \\
\hline & somatosensory & \multicolumn{2}{|c|}{ optical recognition } & \multicolumn{2}{|c|}{ mechanical system } & & \\
\hline Support layer & journal & message & & sdiction & safet & & \\
\hline
\end{tabular}

Figure 5 Electric power security simulation and training platform application framework

The electric practical training platform is mainly composed of the following three applications:

\subsection{D scene application}

The application includes student roles and teacher roles. It has many control and management functions under the teacher's role. The 3D experience and the training content of trainees are realized in the application, as shown in figure 6.

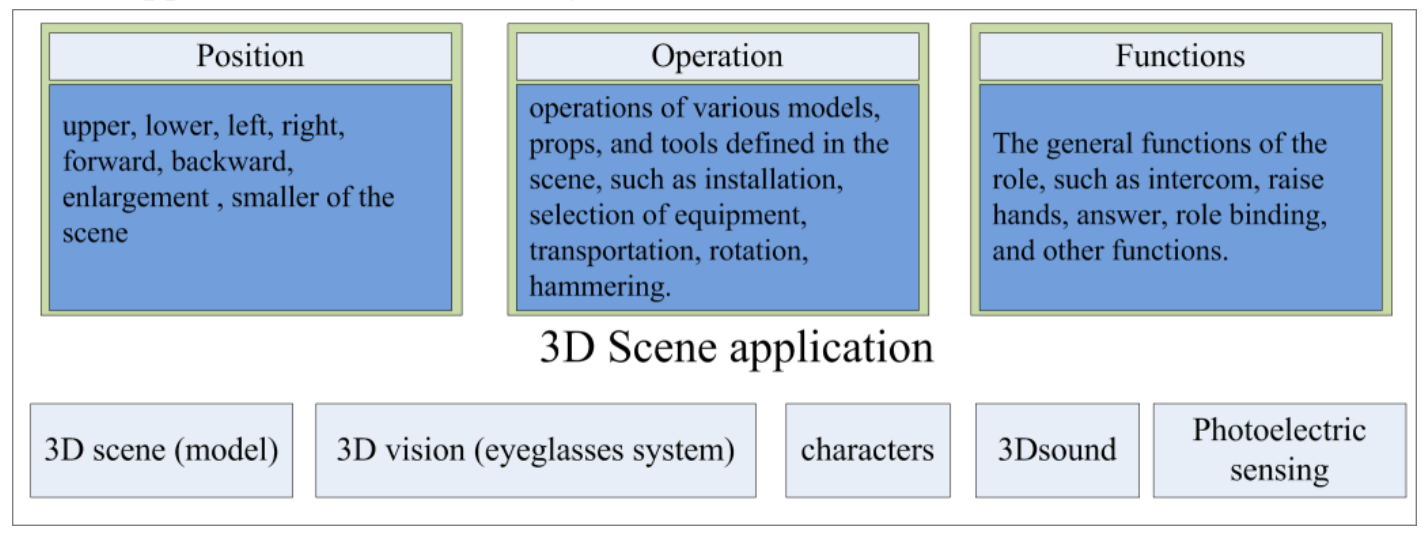

Figure 6 .3D scenarios apply logical topology diagrams

\subsection{The test library, grades, scenarios and user management applications}

The application is primarily used in information management systems. The application is mainly used to manage data and provided maintenance means of data. Such as, the maintenance of test library, the query for the results, the maintenance of the scenario, the user's information maintenance and permissions management. The application uses a typical B/S architecture, uses a Web system plus database system standard schema, and supports multiple mobile application terminals.

\subsection{Mobile application}

This application is mainly used in the mobile terminal application of information management system. The functions of mobile applications include teaching activities, announcements, query scores, downloading learning documents and so on. 


\section{The framework of the training platform technology}

The specific technical framework is shown in Figure 7.

\begin{tabular}{|c|c|c|c|c|c|c|}
\hline $\begin{array}{c}\text { Application } \\
\text { layer }\end{array}$ & $\begin{array}{c}\text { HTML/CCS } \\
\text { (examination questions } \\
\text { display, document display) }\end{array}$ & $\begin{array}{l}\text { HTTP } \\
\text { protocol }\end{array}$ & \multicolumn{2}{|c|}{$\begin{array}{c}\text { JavaScript } \\
\text { (page interaction and control) }\end{array}$} & \multicolumn{2}{|c|}{$\begin{array}{c}\text { Java/JSP } \\
\text { (page content generation } \\
\text { and process control) }\end{array}$} \\
\hline $\begin{array}{c}\text { Software } \\
\text { layer }\end{array}$ & Innomaker3D engine & 3D MAX & Dx9 & NURBS & OpenGL & Photoshop \\
\hline \multirow{2}{*}{$\begin{array}{l}\text { Service } \\
\text { layer }\end{array}$} & Message service & \multicolumn{2}{|c|}{ Ftp file service } & Web service & \multicolumn{2}{|r|}{ DB service } \\
\hline & SMS, WeChat, mail & \multicolumn{2}{|c|}{ FileZilla } & Apache/Tomeat & \multicolumn{2}{|c|}{ MySQL/SQLServer } \\
\hline $\begin{array}{l}\text { Physical } \\
\text { layer }\end{array}$ & $\begin{array}{l}\text { High performance } \\
\text { display system PC }\end{array}$ & \multicolumn{2}{|c|}{$\begin{array}{l}\text { Active shutter type 3D } \\
\text { vision helmet system }\end{array}$} & \multicolumn{2}{|c|}{$\begin{array}{l}\text { Optical hand gesture } \\
\text { recognition system }\end{array}$} & Ethernet system \\
\hline
\end{tabular}

Figure 7 .Power safety simulation and training platform framework

The main technologies of the electric power safety simulation training platform are introduced as follows:

\subsection{D vision system}

With active shutter type 3D Technology, active shutter 3D glasses are used. This 3D technology is most widely used in television and projectors, with relatively large resources and excellent image effects. It has been praised and adopted by many manufacturers.

In general, 3D LCD TV screen refresh rate must reach $120 \mathrm{~Hz}$ or more, that is, so that the left and right eye are receiving the frequency of $60 \mathrm{~Hz}$ or more images, so as to ensure that users see 3D images which is continuous and without flashing.

\subsection{Optical gesture recognition system}

Kinect is somatosensory peripheral peripherals which is officially released by Microsoft XBox360.It is a 3D somatosensory camera, with the introduction of real-time dynamic capture, image recognition, microphone input, speech recognition, community interaction, and other functions. And share pictures and information with other XBox players via the internet. With the help of this technology, the simulation training platform for marketing field operation can integrate the SDK into the training platform to achieve the goal of identifying the immediate status of trainees.

\subsection{File Services and Web Services}

The system uses FileZilla FTP file server and Apache/Tomcat Web server.

\subsection{Innomaker 3D engine}

The Innomaker 3D engine is a new generation of virtual reality platform software developed by ChuangKe Digital Technology Co., Ltd, which can be widely used in interactive training, industrial simulation, visual decision-making, digital city, estate digital planning and sales, restoration of historic sites, emergency rehearsal, military simulation and so on.

Innomaker system is the core software for developing virtual reality software scene and logic function. The software written by $\mathrm{C}++$, mainly using DirectX/Unity and other underlying technology, with strong scalability and stability. The software includes 3D graphics effects and animation, user interface, software and hardware interface, network communication, physical simulation module.

Innomaker offers various solutions of hardware and software integration, such as flat-panel computer screen, simulator, etc. Innomaker is not only practical, easy to operate, powerful, and has 
strong scalability and stability, it has injected new vitality into the field of virtual reality technology.

\subsection{DirectX}

DirectX is a multimedia programming interface created by Microsoft. DirectX is implemented by the $\mathrm{C}++$ programming language and followed by COM. It is widely used in Microsoft Windows, Microsoft Xbox and Microsoft Xbox 360 video game development, and only supports these platforms.

\subsection{D Max}

3D Studio MaxDiscree company developed 3d animation rendering and production software based on PC systems. Its predecessor is a 3D Studio software based on the DOS operating system. It is widely used in advertising, film, industrial design, architectural design, 3d animation, multimedia production, games, auxiliary teaching, engineering visualization and so on.

\section{Training platform physical architecture}

The physical architecture diagram for the system is shown in figure 8 , and the main device configuration and related instructions are shown in table 1.

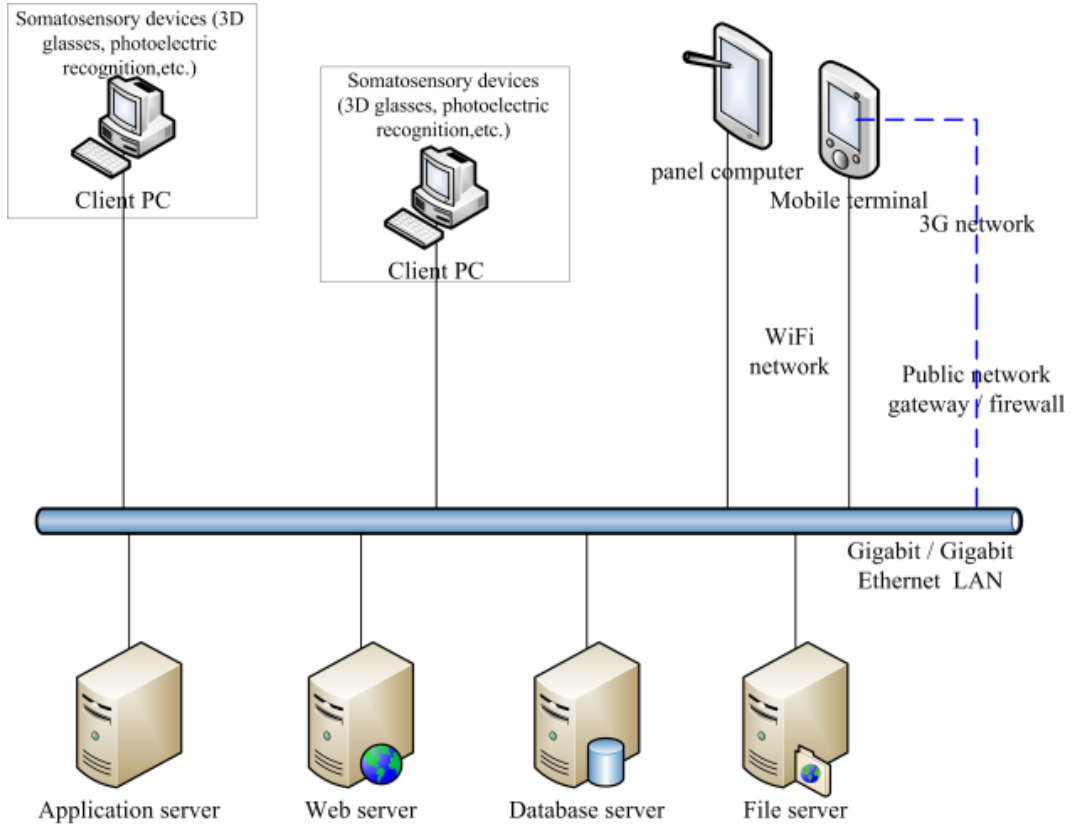

Figure 8 Power safety simulation and training platform framework

Table 1 Simulation and training platform, the main equipment configuration and related instructions

\begin{tabular}{|c|c|c|c|}
\hline Deployment area & Major equipment & Quantity & Purpose \\
\hline \multirow{3}{*}{ Online training room } & $\begin{array}{c}\text { High performance display system } \\
\text { machine }\end{array}$ & 20 & Online training exam \\
\cline { 2 - 4 } & $\begin{array}{c}\text { High performance display system } \\
\text { machine }\end{array}$ & 1 & $\begin{array}{c}\text { Teacher computer and main } \\
\text { display }\end{array}$ \\
\hline \multirow{2}{*}{$\begin{array}{c}\text { Stand-alone } \\
\text { training room }\end{array}$} & Examination machine & 4 & Single machine training test \\
\cline { 2 - 4 } & Immersive learning machine & 1 & Site feeling training \\
\cline { 2 - 4 } & Body feeling learning machine & 1 & Somatosen-sory experience \\
\hline
\end{tabular}

\section{Training Platform Security Architecture}

There are three main strategies of power safety simulation and training platform based on safety architecture.

A. Partition deployment: Following the principle of internal and external network information isolation of State Grid, and deploying Internet business and functional modules in the external 
information network, such as mobile phone termination is deployed in the external information network through 3G mobile network.

B.User registration:Trainees login system requiring the correct user name and password. On the test machine is configured with a fingerprint identification system, only those who are certified by the administrator can enter the system which ensures the appropriate personnel to use the system.

C.Access control:Establishing permission matrix according to the different trainees and training subjects which can avoid inappropriate personnel entering the training module.

\section{Conclusion}

A.In this paper, the computer simulation technology is taking into the electric power marketing skills training system, designing the Casting Technology Field Operation Power Safety Simulation and Training Platform, which provides a new training approach.

B.The application of computer simulation technology can solve the limitation of resources, which focuses on individual training simulation system, and provide a new prospect for future training mode.

C.The synthetic environment concept, which is the basis of simulation system, is also widely accepted by the power enterprises and has broad applicating prospect.

D.This paper also presents the information management system application for the Power Safety Simulation and Training Platform, and provides a means of data maintenance. For instance, the maintenance of the question bank (additions and deletions), the results of the query, the maintenance of the scene and user information, and the management of authority, can effectively improve the efficiency of staff training and the quality of operations.

\section{References}

[1] Xing Wang. Development and Application of Simulation Training System for Transmission and Distribution[D]. 2015, Chongqing:Chongqing University.

[2] Heping Zheng. Design and implementation of the electrified job simulation training system. [D]. 2012, Chengdu: University of Electronic Science and Technology.

[3] Chongjun Zhong. Based on immersive virtual reality power safety training application research [D]. 2013, Beijing: Beijing industry university.

[4]YanbinXie,JingChen,QianZhou.Wireless configuration based safety experience training system for switch cabinet of distribution network[J].2013, ChongQing: State Grid Chongqing power company urban power supply branch.

[5] Xiuqi Cha,Rongquan Wu,Yuanjun Gao.Research on mode conversion from C/S to B/S[J].2014 (01). 